\title{
Utilization of epinephrine-soaked gauzes to address bleeding from osteotomy sites in non-tourniquet total knee arthroplasty: a retrospective cohort study
}

\author{
Hongzhi Liu', Zhaohui Liu', Qidong Zhang ${ }^{2,3}$ and Wanshou Guo $2,3^{*}$
}

\begin{abstract}
Background: Reducing tourniquet inflation time is important because of the complications of tourniquet extensively used for the control of hemorrhage in total knee arthroplasty (TKA). Bleeding management is critical to acquire a relative bloodless arthrotomy interface for maximize cement fixation in non-tourniquet TKA. The purpose of this study was to investigate hemostatic and hemodynamic effects of epinephrine-soaked gauzes in cemented TKAs.

Methods: A retrospective cohort study of 101 patients in two groups was performed. The first group $(n=51)$ underwent unilateral TKA with our procedures of epinephrine use, the second group $(n=50)$ had the same protocol with tourniquet and no epinephrine utilization. Surgical field visualization was assessed by grading scale for difficulty of intraoperative visualization due to blood and number of surgical field clearances. Perioperative blood loss was recorded. Hemodynamic parameters were observed in the epinephrine group.

Results: There was statistically significant difference $(p<0.01)$ on surgeon-rated difficulty in visualization in the epinephrine group between before and after use of epinephrine, and no statistically significant difference $(p=0.96)$ between two groups before cementing. No statistically significant result on numbers of surgical field clearances between two groups ( $p=0.25$ ) was found. Epinephrine group showed significant difference in hidden blood loss compared with no epinephrine group ( $576.6 \pm 229.3$ vs $693.2 \pm 302.9$, respectively, $p=0.04)$. The hemodynamic effects of epinephrine may be under control.

Conclusion: The procedure of epinephrine soaked gauzes, as a prudent adjunct, may be effective to reduce blood loss and obtain bloodless bone sections in non-tourniquet TKAs, regardless of hemodynamics.
\end{abstract}

Keywords: Epinephrine, Tourniquet, Total knee arthroplasty, Hemostatic effects, Hemodynamic

\footnotetext{
* Correspondence: docguowanshou@163.com

${ }^{2}$ Department of Orthopaedic Surgery, China-Japan Friendship Hospital, No. 2,

Yinghuadong Road, Chaoyang District, Beijing 100029, China

${ }^{3}$ Beijing Key Lab Immune-Mediated Inflammatory Diseases, China-Japan

Friendship Hospital, No. 2, Yinghuadong Road, Chaoyang District, Beijing

100029, China

Full list of author information is available at the end of the article
}

(c) The Author(s). 2020 Open Access This article is licensed under a Creative Commons Attribution 4.0 International License, which permits use, sharing, adaptation, distribution and reproduction in any medium or format, as long as you give appropriate credit to the original author(s) and the source, provide a link to the Creative Commons licence, and indicate if changes were made. The images or other third party material in this article are included in the article's Creative Commons licence, unless indicated otherwise in a credit line to the material. If material is not included in the article's Creative Commons licence and your intended use is not permitted by statutory regulation or exceeds the permitted use, you will need to obtain permission directly from the copyright holder. To view a copy of this licence, visit http://creativecommons.org/licenses/by/4.0/. The Creative Commons Public Domain Dedication waiver (http://creativecommons.org/publicdomain/zero/1.0/) applies to the data made available in this article, unless otherwise stated in a credit line to the data. 


\section{Background}

Epinephrine is often used in local infiltration analgesia to reduce systemic absorption of the local anesthetic and prolong the analgesic effect in total knee arthroplasty (TKA) [1-3], and is also used to reduce perioperative blood loss [4, 5]. Epinephrine as a procoagulant has been demonstrated key activities associated with increased fibrinogen release, activation of fibrinogen receptors, and effects on other coagulation factors whose activities are mediated via betaadrenergic receptor. Further research has showed that platelet count increases arise from splenic autotransfusion following low-dose epinephrine infusion via alphaadrenergic receptors [6-8]. Consequently, the whole blood clotting time significantly decreases. Administration of epinephrine is controversial in joint replacement because of a composite of major cardiopulmonary complications including ventricular tachycardia, brokenheart syndrome, pulmonary edema, and intraventricular bleeding [9-11]. However, there has been little discussion about its hemostatic effect as a vasoconstrictor, and hemodynamic effect from administration of epinephrine in TKA procedure.

A pneumatic tourniquet is commonly used in TKA to improve visualization of the operative field, decrease intraoperative blood loss, and enhance the quality of cementation [12, 13]. Even in some tourniquet-free procedures, a tourniquet is also inflated during component cementation because some participating surgeons feel a tourniquet was necessary to minimize blood at the bone-cement interface and maximize fixation. However, acute hypotension and the ischemia-reperfusion (I-R) injury would occur when blood perfusion was reestablished and release of metabolites from the ischemic limb and reduced cardiac preload after deflation of the tourniquet. And it would have a high risk of cardiac and cerebral micro emboli, a high risk of deep venous thrombosis, and an increased incidence of arterial thrombosis especially for the elderly undertaking TKA who have multiple comorbidities [14].

Therefore, for a tourniquet-free TKA protocol, our attempt was made to establish a set of intra-surgical procedures that can provide a satisfying visualization and a relatively bloodless bone interface for cementation with the topical hemostatic agent of epinephrine solution. Furthermore, epinephrine-related side effects associated with adverse cardiopulmonary complications may be fatal in rare cases and cautious hemodynamic monitoring is needed. The purpose of this study was to determine the hemostatic effect of epinephrine-soaked gauzes by comparing surgical field visualization between patients receiving epinephrine and those undergoing tourniquet. We hypothesized that epinephrine-soaked gauzes would be sufficient to reduce blood loss and obtain bloodless bone sections in patients undergoing non-tourniquet cemented TKA.

\section{Methods \\ Patient selection}

This study protocol has been approved by the IRB of the authors' affiliated institutions. This is a retrospective cohort study of 143 patients who underwent a primary unilateral cemented TKA from January 1, 2018 to December 31, 2019 in our hospital. From the final analysis patients with prior surgery involving the femur or tibia, prior lower extremity fracture, coagulopathy and uncontrolled hypertension, history of myocardial infarction or stroke, and bilateral total knee arthroplasty were excluded. In the final analysis, a total of 101 patients fulfilled the study inclusion criteria and were available. The patients were analyzed in 2 groups. In the first group, one tourniquet was not used but prepared for bleeding out of control and gauzes soaked with 1-mg epinephrine mixed with $125-\mathrm{mL}$ normal saline solution (dilution 1:125,000) were utilized to cover and pressurize for hemostasis on the osteotomized surface of the distal femoral and proximal tibial bones from the finish of bone resections to the start of cementing (Fig. 1). In the second group, one pneumatic tourniquet placed high on

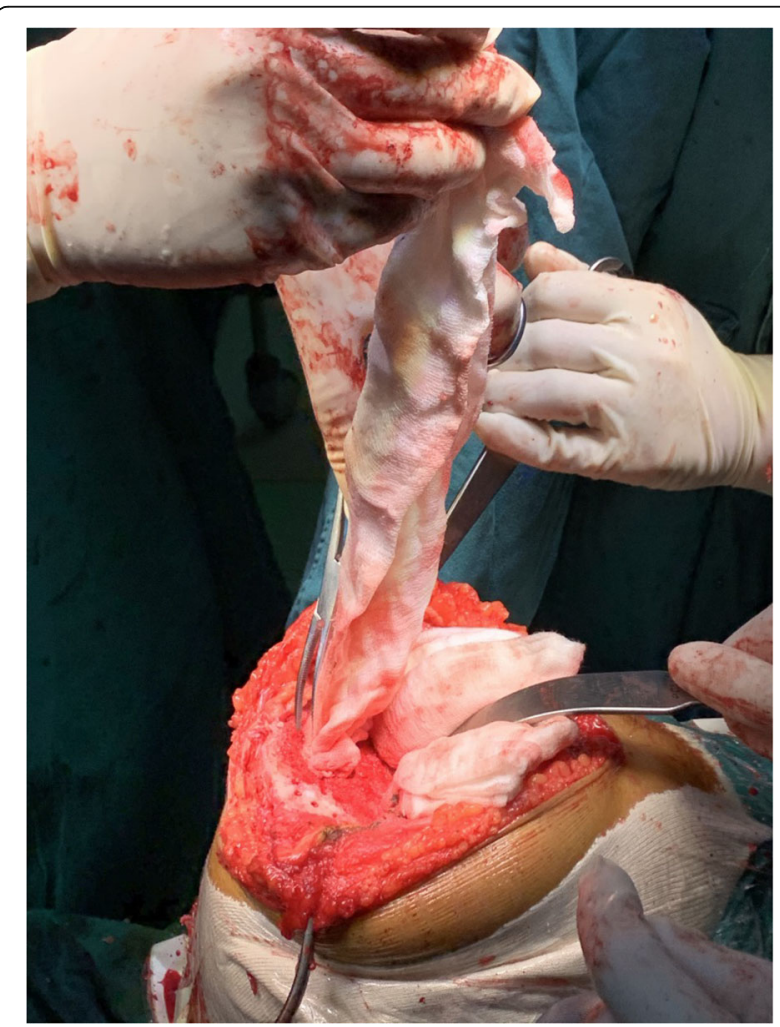

Fig. 1 Epinephrine-soaked gauzes are covered and pressurized on osteotomy sites of femur and tibia to address bleeding 
the thigh was inflated to $250 \mathrm{mmHg}$ before the skin incision and deflated after the cement was completely polymerized. All other aspects of perioperative care were constant throughout the groups.

\section{Perioperative management}

All the operations were performed with a fixed plant posterior-stabilized total knee prosthesis in a medial parapatellar approach. A general anesthetic with an adductor canal block was used for all the patients [15]. And appropriate perioperative parenteral antibiotics were administered for infection prophylaxis. High-pressure pulsatile lavage was used to clean the bone surfaces and soft tissues. Before wound closure, all knees received an intraarticular injection of a cocktail containing ropivacaine, morphine, and ketorolac to enhance postoperative analgesia without drain insertion. Elastic compressive dressing was also used. Each patient received the same perioperative regimen: tranexamic acid (TXA), pain control and rehabilitation. All patients received 1-g intravenous tranexamic acid $30 \mathrm{~min}$ before skin incision, and a solution of $1-\mathrm{g}$ tranexamic acid in $50-\mathrm{mL}$ normal saline solution was injected into knee articular cavity after closure of the capsule [16]. Multimodal postoperative pain management and accelerated physical therapy were performed as previously described. Low molecular weight heparin (enoxaparin, $3000 \mathrm{IU}$ ) was administered subcutaneously $12 \mathrm{~h}$ after the operation and was continued for 2 weeks for thrombosis prophylaxis. After recovery from anesthesia, quadriceps femoris muscle isometric contraction was immediately started, and rehabilitation began on the first postoperative day, including muscle power training.

\section{Outcome measurement}

The primary outcomes of the study were surgical field visualization including surgeon-rated difficulty in visualization and number of surgical field clearances $[17$, 18]. Surgeon-rated difficulty in visualization prior to using epinephrine in Epinephrine group and before cementing in two groups, was graded (Grading scale for difficulty of intraoperative visualization due to blood: 0 No Difficulty; 1 Some difficulty, but did not affect the case; 2 Moderate difficulty; 3 Severe difficulty), and independently assessed by two senior authors (Z. L. and W. G.) at the end of the surgery; Number of surgical field clearances (excluding action of using epinephrine-soaked gauzes) was counted by another author (H. L.) in two groups over the period from the finish of bone cutting through the cement hardening. Any disagreement was resolved by a consensus among all authors.

Perioperative blood loss was the secondary outcome. Volumes of intraoperative blood loss, postoperative blood loss, blood transfusion, and hidden blood loss were recorded. The blood volume of each patient was calculated by a formula that consists of patient weight, height and sex [19]. The blood loss was calculated on the basis of the validated Gross formula [20]. Hematocrit (Hct) and hemoglobin $(\mathrm{Hb})$ levels were determined preoperatively and on postoperative day 2 . The intraoperative blood loss represented by the increased weight of the gauzes plus the volume in the aspirator bottle excluding rinse. The amounts of postoperative visible blood loss were calculated by weighing the dressings removed after the surgery. Intraoperative characteristics included the surgery time duration (beginning at incision until emergence from anesthesia), tourniquet time were noted. Meanwhile, in the epinephrine group, incidences of hypertension, hypotension and tachycardia were evaluated. Hemodynamic parameters at 5-min intervals for 15 min since timing of application of the epinephrine were recorded. At 4 weeks after surgery (the first postoperative follow-up visit), the incidence of symptomatic deep vein thrombosis (DVT), symptomatic pulmonary embolism (PE) and other complications, such as subcutaneous hematoma, skin complications (blisters, bruises, superficial and deep wound infection), myocardial infarction, and cerebrovascular accident, were assessed.

\section{Statistical analyses}

Data were entered into an Access Case Report Form database and further analyzed by $\mathrm{R}$ software (version 3.6.3, The R Foundation, Vienna, Austria). Quantitative data are presented as the mean and standard deviation (SD); categorical variables are used as proportions. Differences in continuous variables between groups were evaluated with Independent-Sample $\mathrm{T}$ test or MannWhitney $U$ test, depending on the distribution characteristics of the data. A chi-square test or Fisher exact test for difference in proportions was used to estimate the differences between groups in categorical variables. Values of $p<0.05$ were considered to be statistically significant.

\section{Results}

There were no significant differences $(p>0.05)$ found at baseline with regard to age, body mass index (BMI), sex, American Society of Anesthesiologists (ASA) class, mean starting hemoglobin, or preoperative diagnosis between the groups. In this study, 101 patients were available, as shown in Table 1: 51 in the epinephrine group, and 50 in the no epinephrine group. The tourniquet time for the tourniquet group was $61.1 \mathrm{~min}$. The mean operating time for the epinephrine group $(81.6 \mathrm{~min})$ and the no epinephrine group $(80.9 \mathrm{~min})$ was not significantly 
Table 1 Patient demographic characteristics

\begin{tabular}{|c|c|c|c|}
\hline & Epinephrine group $(N=51)$ & No epinephrine group $(N=50)$ & $P$ value \\
\hline $\operatorname{Age}^{a}(y r)$ & $67.1(8.6)$ & $66.8(8.9)$ & $0.88+$ \\
\hline $\operatorname{Sex}^{b}$ & & & $0.34 \#$ \\
\hline Male & $4(7.8 \%)$ & $8(16.0 \%)$ & \\
\hline Female & $47(92.2 \%)$ & $42(84.0 \%)$ & \\
\hline $\mathrm{BMl} l^{\mathrm{a}}(\mathrm{kg} / \mathrm{m} \wedge 2)$ & $25.8(3.2)$ & $26.2(3.4)$ & $0.55 \dagger$ \\
\hline Starting hemoglobin ${ }^{\mathrm{a}}(\mathrm{g} / \mathrm{dL})$ & $131.8(12.3)$ & $132.4(14.3)$ & $0.22+$ \\
\hline ASA classification ${ }^{b}$ & & & $0.32 \S$ \\
\hline 1 (normal, healthy) & $20(39.2 \%)$ & 19 (38.0\%) & \\
\hline 2 (mild, systemic disease) & $30(58.8 \%)$ & $29(58.0 \%)$ & \\
\hline 3 (severe systemic disease) & $1(2.0 \%)$ & $3(6.0 \%)$ & \\
\hline Preoperative diagnosis $^{\mathrm{b}}$ & & & $0.99^{* *}$ \\
\hline Osteoarthritis & $50(98.0 \%)$ & $48(96.0 \%)$ & \\
\hline Rheumatoid arthritis & $1(2.0 \%)$ & $2(4.0 \%)$ & \\
\hline Tourniquet time ${ }^{a}(\mathrm{~min})$ & NA & $61.1(7.8)$ & \\
\hline Operating time ${ }^{a}(\min )$ & $81.6(12.1)$ & $80.9(9.3)$ & $0.76+$ \\
\hline Follow-up duration ${ }^{a}$ (day) & $28.5(2.5)$ & $28.2(2.6)$ & $0.41 \dagger$ \\
\hline
\end{tabular}

${ }^{a}$ The values are given as the mean and the standard deviation

${ }^{\mathrm{b}}$ The values are given as the number of patients, with the percentage in parentheses

†Significance was determined with use of Independent-Sample T test

$\S$ Significance was determined with use of the Mann-Whitney $U$ test

\# Significance was determined with use of the chi-square test

** Significance was determined with use of the Fisher exact test

different $(p=0.76)$. There was no significant betweengroup difference in follow-up duration $(p=0.41)$.

In terms of surgical field visualization, there was statistically significant difference $(p<0.01)$ on surgeonrated difficulty in visualization in the epinephrine group between before and after use of epinephrine, and no statistically significant differences $(p=0.96)$ between two groups before cementing (Table 2). We also found no statistically significant result on numbers of surgical field clearances between two groups $(p=0.25)$ (Table 3).

Table 4 shows that the epinephrine group had significantly less hidden blood loss $(p=0.04)$ than the no epinephrine group. There was no between-group difference in the calculated blood loss $(p=0.26)$, intraoperative blood loss $(p=0.87)$. Two patients in the no epinephrine group, and 2 patients in the epinephrine group received a blood transfusion.

The incidence of hemodynamic instability after application of epinephrine, including hypertension, hypotension, and tachycardia, is shown in Table 5 . Figure 2 presents the changes in hemodynamic parameters, including systolic blood pressure (SBP), mean blood pressure (MBP), and heart rate (HR), at 5-min intervals from timing of use of the epinephrine to $15 \mathrm{~min}$ following that.

Table 2 Surgeon-rated difficulty in visualization

\begin{tabular}{|c|c|c|c|c|c|}
\hline & \multicolumn{2}{|l|}{ Before Epinephrine $^{a}$} & \multicolumn{2}{|l|}{ Before Cementing $^{a}$} & \multirow[t]{2}{*}{$P$ value } \\
\hline & $\begin{array}{l}\text { Epinephrine group } \\
(N=51)\end{array}$ & $\begin{array}{l}\text { No epinephrine group } \\
(N=50)\end{array}$ & $\begin{array}{l}\text { Epinephrine group } \\
(N=51)\end{array}$ & $\begin{array}{l}\text { No epinephrine group } \\
(N=50)\end{array}$ & \\
\hline 0 No Difficulty & $0(0.0 \%)$ & NA & $42(82.3 \%)$ & $41(82.0 \%)$ & \multirow{4}{*}{$\begin{array}{l}<0.01 \S \neq \\
0.96 \S \# \#\end{array}$} \\
\hline 1 Some difficulty, but did not affect the case & $6(11.8 \%)$ & NA & $8(15.7 \%)$ & $8(16.0 \%)$ & \\
\hline 2 Moderate difficulty & $12(23.5 \%)$ & NA & $1(2.0 \%)$ & $1(2.0 \%)$ & \\
\hline 3 Severe difficulty & $33(64.7 \%)$ & NA & $0(0.0 \%)$ & $0(0.0 \%)$ & \\
\hline
\end{tabular}

${ }^{a}$ The values are given as the number of patients, with the percentage in parentheses

$\S$ Significance was determined with use of the Mann-Whitney $U$ test

\# P value was calculated for difference in Epinephrine group between before and after use of epinephrine

\#\# $P$ value was calculated for difference between Epinephrine and No Epinephrine groups before cementing 
Table 3 No of surgical field clearances

\begin{tabular}{llll}
\hline & Epinephrine group $(N=51)$ & No epinephrine group ${ }^{\mathrm{a}}(N=50)$ & $P$ value \\
\hline None & $17(33.3 \%)$ & $21(55.3 \%)$ \\
$1-3$ cycles & $29(56.9 \%)$ & $27(48.2 \%)$ \\
$>3$ cycles & $5(9.8 \%)$ & $2(28.6 \%)$ \\
\hline
\end{tabular}

${ }^{a}$ The values are given as the number of patients, with the percentage in parentheses

$\S S$ ignificance was determined with use of the Mann-Whitney $U$ test

Postoperative deep venous thrombosis and other complication percentages in each group are presented in Table 6. Two patients in in the no epinephrine group developed skin blisters and 2 other patients did bruises. No patients had superficial or deep wound infection, myocardial infarction, or cerebrovascular accident postoperatively.

\section{Discussion}

We found that ideal bloodless visualization of the operative field was obtained in the epinephrine group, comparing that in epinephrine group between before and after use of epinephrine and in two groups prior to cementing. We also found that the use of epinephrine resulted in reducing postoperative hidden blood loss significantly and hemodynamic parameters fluctuated under control in patients receiving epinephrine.

In terms of topical control of blood loss in TKA, epinephrine solution, TXA, and many hemostatic gels and powders have been advocated to address bleeding recently [21]. The combined administration of low-dose epinephrine and TXA also demonstrated an increased effect in reducing perioperative blood loss and the inflammatory response [22]. All of these methods have been used to reduce the need for allogenic transfusion. However, none of these methods was used to address bleeding from osteotomy sites for visualization and cementing.
Vasoconstriction effect of epinephrine is complex, and vasoconstriction intensity differs depending on vessel type: arteries, arterioles, precapillary sphincters, capillaries, venules, and veins [23]. It is conceivable that the use of vasoconstrictor epinephrine might predispose to delayed intraoperative bleeding, by temporarily blocking vessels that later start bleeding when the initial vasoconstrictor effect has passed. Though epinephrine's maximal effect on arterial vasoconstriction may work at 7 to 10 min, it takes considerably longer for a new local equilibrium to be obtained with regard to hemoglobin quantity. If optimal visualization and fixation are desired, the ideal time for cement hardening should be the time when local hemoglobin concentration is lowest [24, 25]. Therefore, it is sufficient for fully cementing all areas of contact of the tibia and femur by preparing cement, applying it to both the bone and the component surfaces, then holding components carefully in place until the cement has completely polymerized. On top of that, there was no evidence of any rebound bleeding in the postoperative period in any of our patients, as an indication in the nearly equal volume of intraoperative blood loss that occurred. This finding also suggests that the use of epinephrine does not increase the risk of intraoperative rebound bleeding with good hemostasis for the occurrence of the roughly same volume of intraoperative blood loss.

The present study showed topical use of epinephrinesoaked gauzes induced a significant reduction of

Table 4 Comparison of differences in blood loss

\begin{tabular}{llll}
\hline & Epinephrine group $(N=51)$ & No epinephrine group $(N=50)$ & $P$ value \\
\hline Calculated blood loss ${ }^{\mathrm{a}}(\mathrm{mL})$ & $735.9(293.7)$ & $847.7(333.8)$ & $0.26+$ \\
Intraoperative blood loss $^{\mathrm{a}}(\mathrm{ml})$ & $175.3(83.7)$ & $170.5(80.9)$ & $0.87 \dagger$ \\
Hidden blood loss ${ }^{\mathrm{a}} \#(\mathrm{ml})$ & $576.6(229.3)$ & $693.2(302.9)$ & $0.04 \dagger$ \\
Transfusion & & & $0.99 \S$ \\
$\quad$ None & $49(96.1 \%)$ & $48(96 \%)$ & $0(0.0 \%)$ \\
2 unit & $0(0.0 \%)$ & $2(4.0 \%)$
\end{tabular}

${ }^{\mathrm{a}}$ The values are given as the mean and the standard deviation

${ }^{\mathrm{b}}$ The values are given as the number of patients, with the percentage in parentheses

†Significance was determined with use of Independent-Sample T test

§significance was determined with use of the Fisher exact test

\# PBV (Patient's blood volume $)=\mathrm{k} 1 \times$ height $\wedge 3(\mathrm{~m})+\mathrm{k} 2 \mathrm{x}$ weight $(\mathrm{kg})+\mathrm{k} 3$, where $\mathrm{k} 1=0.3669, \mathrm{k} 2=0.03219$, and $\mathrm{k} 3=0.6041$ for $\mathrm{men}$; and $\mathrm{k} 1=0.3561, \mathrm{k} 2=$

0.03308 , and $\mathrm{k} 3=0.1833$ for women; Total blood loss $=$ PBV $x$ (preoperative $\mathrm{Hct}$ - postoperative Hct)

\#\# Hidden blood loss = Total blood loss - Intraoperative blood loss + Allogeneic blood transfusion 
Table 5 Incidences of hemodynamic instabilities after application of the epinephrine

\begin{tabular}{ll}
\hline & Epinephrine group $^{\mathrm{a}}(\mathrm{N}=51)$ \\
\hline Systolic BP $>190 \mathrm{mmHg}$ or mean BP $>140 \mathrm{mmHg}$ & $0(0.0 \%)$ \\
Systolic BP $>140 \mathrm{mmHg}$ or mean BP $>110 \mathrm{mmHg}$ & $6(11.8 \%)$ \\
Systolic BP increase of $20 \%$ from baseline & $4(7.8 \%)$ \\
Systolic BP $<90 \mathrm{mmHg}$ or mean BP $<60 \mathrm{mmHg}$ & $7(13.7 \%)$ \\
Tachycardia (heart rate $>100$ beats per minute) & $1(2.0 \%)$ \\
\hline
\end{tabular}

${ }^{\mathrm{a}}$ The values are given as the number of patients, with the percentage in parentheses. $B P$ Blood pressure

perioperative hidden blood loss compared with utilization of tourniquet. Epinephrine as a plateletstimulating agent can cause aggregation of human platelets through alpha-adrenergic mechanisms [8]. It can explain the effectiveness of this procoagulant in decreasing postoperative blood loss because of its hemostatic effect [26]. Moreover, insufficient intraoperative hemostasis under tourniquet and tourniquet release further promote local fibrinolysis, which may result in further blood loss [27].

This method was characterized by the absence of complications and adverse reactions associated with epinephrine. Hemodynamic parameters in our study fluctuated under control in patients receiving epinephrine. Peak changes in HR, MBP, SBP were observed to reached $10 \mathrm{~min}$ following the beginning of the epinephrine use, and the original values were decreased to at approximately $15 \mathrm{~min}$ from start.
Tissue ischemia, infection and skin necrosis were also not detected in the epinephrine group.

This study had several limitations. First, regarding the concentration and technique of epinephrine solution, there is no consensus. To our knowledge, there is not a single study with outcome measurements that epinephrine is used for hemostasis in the osteotomized sites. A body of previous studies have reported subcutaneous injection of epinephrine solutions in concentrations up to 1:50,000 with good effect in burn and hand surgery [2831 , and even higher concentration has been safely used in other forms of surgery [32, 33]. We empirically prepared an epinephrine solution at a concentration of 1 : 125,000 which was higher than that in some orthopaedic surgery, on the basis of consideration that effective drug concentration was longer for cement hardening before it wore off. Meanwhile, the tumescent technique as it applies to suction lipectomy of plastic surgery has been
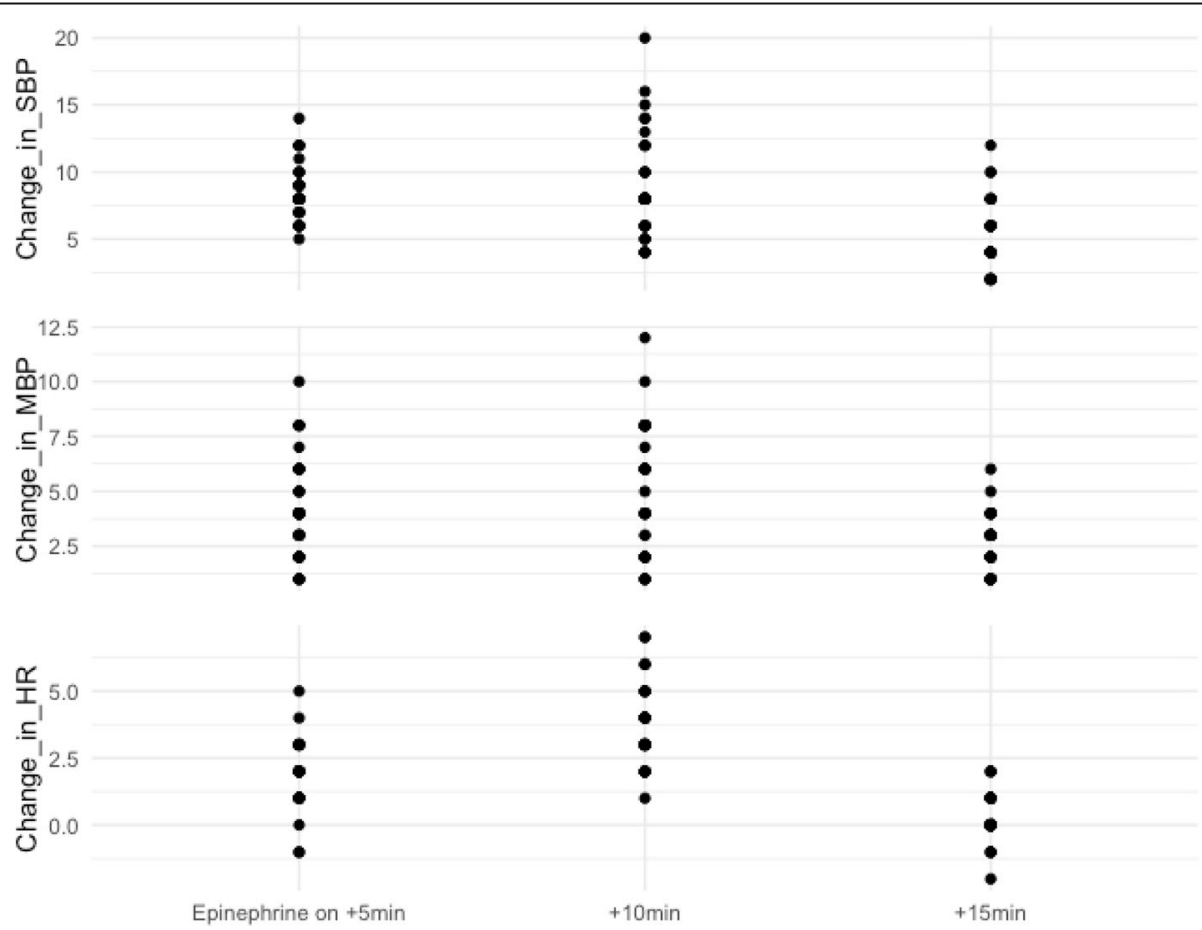

Fig. 2 Hemodynamic parameters at 5-min intervals for 15 min since timing of application of the epinephrine. HR, heart rate; MBP, mean blood pressure; SBP, systolic blood pressure 
Table 6 Complications

\begin{tabular}{|c|c|c|c|}
\hline & Epinephrine group ${ }^{a}(N=51)$ & No epinephrine group $(N=50)$ & $P$ value \\
\hline \multicolumn{3}{|c|}{ Deep venous thrombosis or pulmonary embolism } & $0.24 \S$ \\
\hline None & $51(100 \%)$ & $48(96 \%)$ & \\
\hline Deep venous thrombosis & $0(0 \%)$ & $2(4 \%)$ & \\
\hline Pulmonary embolism & $0(0 \%)$ & $0(0 \%)$ & \\
\hline \multicolumn{3}{|l|}{ Other complications ${ }^{\mathrm{b}}$} & $0.52 \S$ \\
\hline None & $49(96.1 \%)$ & $45(90.0 \%)$ & \\
\hline Subcutaneous hematoma & $1(1.9 \%)$ & $1(2.0 \%)$ & \\
\hline \multicolumn{4}{|l|}{ Skin complications } \\
\hline Blisters & $0(0.0 \%)$ & $2(4.0 \%)$ & \\
\hline Bruises & $1(1.9 \%)$ & $2(4.0 \%)$ & \\
\hline
\end{tabular}

${ }^{a}$ The values are given as the number of patients, with the percentage in parentheses

${ }^{b}$ No patients in the data set were recorded as having superficial infection, deep infection aseptic loosening, myocardial infarction, or cerebrovascular accident as other complications

§Significance was determined with use of the Fisher exact test

more extensively studied, but these data are not directly applicable to orthopaedic cases as much of the epinephrine is used in bone cut $[34,35]$. Hence, we attempted to utilize the technique of epinephrine, soaking not infiltrating, on the osteotomized surfaces, because tumescent or infiltrating technique was abandoned for such adverse effects of epinephrine as delaying wound healing, increasing the risk of infection, and compromising flap survival. Then, the incidence of hemodynamic instability may have been obscured because we merely investigated hemodynamic parameters at 5-min intervals only for $20 \mathrm{~min}$ since application of the epinephrine and bone cement may adversely affect hemodynamics. Furthermore, short-, medium-, and long-term outcomes outcome following TKA is needed to evaluate whether the epinephrine procedure will compromise prothesis survival or not. Additionally, since we did not have a control group without a tourniquet and epinephrine both together, hence we may not assess the net effect of epinephrine regardless of physiological hemostasis, if any. Finally, we failed to find any significant differences in the incidence of postoperative complications, this might be due to a relatively small sample size or lack of clinical implication. Further large-scale studies on high-risk patients are needed to assess the association between intra- and postoperative cardiovascular complications and the use of epinephrine.

\section{Conclusion}

The procedure of epinephrine-soaked gauzes can result in an effective form of addressing blood oozing from cut bone planes, while it does not lead to apparent hemodynamic oscillations and vigilant hemodynamic monitoring is a necessity. The utilization of epinephrine- soaked gauzes seems to have an advantage in terms of great potential for a complete tourniquet-free procedure, regardless of hemodynamics.

\section{Abbreviations \\ ASA: American Society of Anesthesiologists; BMl: Body mass index; BP: Blood pressure; CTPA: Computed tomography pulmonary angiogram; DVT: Deep vein thrombosis; Hb: Hemoglobin; Hct: Hematocrit; HR: Heart rate; MBP: Mean blood pressure; PE: Pulmonary embolism; SBP: Systolic blood pressure; TKA: Total knee arthroplasty; TXA: Tranexamic acid}

\section{Acknowledgments}

Not applicable.

\section{Authors' contributions}

H.L. contributed to the conception and design of the study, the acquisition of data, interpretation of the results and writing the final manuscript. Z.L. contributed to the conception and design of the study, the acquisition of data, interpretation of the results and writing the final manuscript. Q.Z. contributed to data extraction from the database and the data statistical analysis. W.G. contributed to the conception and design of the study, provided a critical revision of the manuscript. All authors read and approved the final manuscript.

\section{Funding}

This study was funded by National Natural Science Foundation of China (grant number 81703896, 81673776), Beijing municipal science and technology commission (grant number Z171100001017209), and the Capital Health Research and Development of Special (grant number 2016-2-4062).

The Fund's role is to provide review and publishing costs.

Availability of data and materials

The datasets used and/or analyzed during the current study are available from the corresponding author on reasonable request.

Ethics approval and consent to participate

China-Japan Friendship Hospital institutional review board approved this study. Application number: 2013-SF-1. A written consent was obtained by all patients who participated in this study.

\section{Consent for publication}

All patients provided consent to participate in this study, per our institution's standard for research consent forms, this consent specified that the research information obtained may be used for publication. 


\section{Competing interests}

The authors declare that they have no competing interests.

\section{Author details}

'Beijing University of Chinese Medicine, 11 N 3rd Ring Rd E, Chaoyang District, Beijing, China. ${ }^{2}$ Department of Orthopaedic Surgery, China-Japan Friendship Hospital, No. 2, Yinghuadong Road, Chaoyang District, Beijing 100029, China. ${ }^{3}$ Beijing Key Lab Immune-Mediated Inflammatory Diseases, China-Japan Friendship Hospital, No. 2, Yinghuadong Road, Chaoyang District, Beijing 100029, China.

\section{Received: 17 April 2020 Accepted: 17 August 2020}

Published online: 25 August 2020

\section{References}

1. Mc Cartney CJ, Mc Leod GA. Local infiltration analgesia for total knee arthroplasty. Br J Anaesth. 2011;107:487-9.

2. Andersen LO, Kehlet $\mathrm{H}$. Analgesic efficacy of local infiltration analgesia in hip and knee arthroplasty: a systematic review. Br J Anaesth. 2014; 113:360-74.

3. Fenten MGE, Bakker SMK, Touw DJ, et al. Pharmacokinetics of $400 \mathrm{mg}$ ropivacaine after periarticular local infiltration analgesia for total knee arthroplasty. Acta Anaesthesiol Scand. 2017;61(3):338-45.

4. Jans $\varnothing$, Grevstad U, Mandøe $H$, Kehlet $H$, Johansson PI. A randomized trial of the effect of low dose epinephrine infusion in addition to tranexamic acid on blood loss during total hip arthroplasty. Br J Anaesth. 2016;116(3): 357-62

5. Gao F, Sun W, Guo W, Li Z, Wang W, Cheng L. Topical application of tranexamic acid plus diluted epinephrine reduces postoperative hidden blood loss in total hip arthroplasty. J Arthroplast. 2015;30(12):2196-200.

6. Bakovic D, Pivac N, Eterovic D, Breskovic T, Zubin P, Obad A, Dujic Z. The effects of low-dose epinephrine infusion on spleen size, central and hepatic circulation and circulating platelets. Clin Physiol Funct Imaging. 2013;33(1):30-7.

7. von Känel R, Dimsdale JE. Effects of sympathetic activation by adrenergic infusions on hemostasis in vivo. Eur J Haematol. 2000;65(6):357-69.

8. Yun-Choi HS, Park KM, Pyo MK. Epinephrine induced platelet aggregation in rat platelet-rich plasma. Thromb Res. 2000;100(6):511-8.

9. Toivonen J, Pitko VM, Rosenberg PH. Comparison between intra-articular bupivacaine with epinephrine and epinephrine alone on short-term and long-term pain after knee arthroscopic surgery under general anesthesia in day-surgery patients. Acta Anaesthesiol Scand. 2002;46:435-40.

10. Belkin NS, Degen RM, Liguori GA, Kelly BT. Epinephrine-induced pulmonary edema during hip arthroscopy: a report of two cases and a review of the literature. Phys Sports med. 2017:45:353-6.

11. Mazzocca AD, Meneghini RM, Chhablani R, et al. Epinephrine-induced pulmonary edema during arthroscopic knee surgery: a case report. J Bone Joint Surg Am. 2003;85(5):913-5.

12. Tai TW, Lin CJ, Jou IM, Chang CW, Lai KA, Yang CY. Tourniquet use in total knee arthroplasty: a meta-analysis. Knee Surg Sports Traumatol Arthrosc. 2011;19(7):1121-30.

13. Chen S, Li J, Peng H, Zhou J, Fang $H$, Zheng $H$. The influence of a halfcourse tourniquet strategy on peri-operative blood loss and early functional recovery in primary total knee arthroplasty. Int Orthop. 2014;38:355-9.

14. Maradit Kremers H, Larson DR, Crowson CS, Kremers WK, Washington RE, Steiner CA, et al. Prevalence of total hip and knee replacement in the United States. J Bone Joint Surg Am. 2015;97(17):1386-97.

15. Seruya M, Oh AK, Rogers GF, Boyajian MJ, Myseros JS, Yaun AL, Keating RF. Controlled hypotension and blood loss during frontoorbital advancement. J Neurosurg Pediatr. 2014;9(5):491-6.

16. Yang ZG, Chen WP, Wu LD. Effectiveness and safety of tranexamic acid in reducing blood loss in total knee arthroplasty: a meta-analysis. J Bone Joint Surg Am. 2012;94(13):1153-9.

17. Goel R, Rondon AJ, Sydnor K, Blevins K, O'Malley M, Purtill JJ, et al. Tourniquet use does not affect functional outcomes or pain after total knee arthroplasty: a prospective, double-blinded, randomized controlled trial. J Bone Joint Surg Am. 2019;101:1821-8.

18. Na YG, Bamne AB, Won HH, Kim TK. (2015) after early release of tourniquet in total knee arthroplasty, should it be reinflated or kept deflated? A randomized trial. Knee Surg Sports Traumatol Arthrosc. 2015;25(9):2769-77.
19. Nadler SB, Hidalgo JH, Bloch T. Prediction of blood volume in normal human adults. Surgery. 1962:51(2):224-32

20. Gross JB. Estimating allowable blood loss: corrected for dilution. Anesthesiology. 1983;58(3):277-80.

21. Helito CP, Bonadio MB, Sobrado MF, Giglio PN, Pécora JR, Camanho GL, et al. Comparison of Floseals ${ }^{\oplus}$ and tranexamic acid for bleeding control after total knee arthroplasty: a prospective randomized study. Clinics. 2019; 74:e1186.

22. Zeng WN, Liu JL, Wang FY, Chen C, Zhou Q, Yang L. Low-dose epinephrine plus tranexamic acid reduces early postoperative blood loss and inflammatory response: a randomized controlled trial. J Bone Joint Surg Am. 2018;100:295-304

23. Lee RE, Holze EA. The peripheral vascular system in the bulbar conjunctiva of young normotensive adults at rest. J Clin Invest. 1950;29:146-50.

24. Gibson M. Outpatient carpal tunnel decompression without tourniquet: A simple local anaesthetic technique. Ann R Coll Surg Engl. 1990;72:408-9.

25. McKee DE, Lalonde $\mathrm{DH}$, Thoma $\mathrm{A}$, et al. Optimal time delay between epinephrine injection and incision to minimize bleeding. Plast Reconstr Surg. 2013;131:811.

26. Gasparini G, Papaleo P, Pola $P$, et al. Local infusion of norepinephrine reduces blood losses and need of transfusion in total knee arthroplasty. Int Orthop. 2006:30:253.

27. Benoni $\mathrm{G}$, Lethagen $\mathrm{S}$, Fredin $\mathrm{H}$. The effect of tranexamic acid on local and plasma fibrinolysis during total knee arthroplasty. Thromb Res. 1997;85(3): 195-206.

28. Bezuhly M, Sparkes GL, Higgins A, Neumeister MW, Lalonde DH. Immediate thumb extension following extensor indicis proprius to extensor pollicis longus tendon transfer using the wide-awake approach. Plast Reconstr Surg. 2007;119:1507-12

29. Higgins A, Lalonde HD, Bell M, McKee D, Lalonde JF. Avoiding flexor tendon repair rupture with intraoperative total active movement examination. Plast Reconstr Surg. 2010;126:941-5.

30. McKee DE, Lalonde DH, Thoma A, Dickson L. Achieving the optimal epinephrine effect in wide awake hand surgery using local anesthesia without tourniquet. Hand. 2015:10:613-5.

31. Bashir MM, Qayyum R, Saleem MH, Siddique K, Kahn FA. Effect of time interval between tumescent local anesthesia infiltration and start of surgery on operative field visibility in hand surgery without tourniquet. J Hand Surg Am. 2015:40:1606-9.

32. De Bono R, Rao GS. Vasoconstrictor infiltration in breast reduction surgery: is it harmful? Br J Plast Surg. 1997;50:260-2.

33. Steele MH. Three-year experience using near infrared spectroscopy tissue oximetry monitoring of free tissue transfer. Ann Plast Surg. 2011;66:540-5.

34. Klein JA. The tumescent technique. Anesthesia and modified liposuction technique. Dermatol Clin. 1990;8:425-37.

35. Budny PG, Regan PJ, Roberts AHN. The estimation of blood loss during burns surgery. Burns. 1993;19:134-7.

\section{Publisher's Note}

Springer Nature remains neutral with regard to jurisdictional claims in published maps and institutional affiliations.

Ready to submit your research? Choose BMC and benefit from:

- fast, convenient online submission

- thorough peer review by experienced researchers in your field

- rapid publication on acceptance

- support for research data, including large and complex data types

- gold Open Access which fosters wider collaboration and increased citations

- maximum visibility for your research: over $100 \mathrm{M}$ website views per year

At BMC, research is always in progress.

Learn more biomedcentral.com/submission 